\title{
PENGARUH POTENSI SUMBERDAYA AIR TERHADAP POLA PENGGUNAAN KEBUTUHAN DOMESTIK DI KECAMATAN EROMOKO KABUPATEN WONOGIRI
}

\author{
Pujo Nur Cahyo ${ }^{1}$, M. Pramono Hadi ${ }^{2}$, dan Tjahyo Nugroho Adji ${ }^{3}$
}

Kementrian Lingkungan Hidup dan Kehutanan, Jakarta, Indonesial, Fakultas Geografi, Universitas Gadjah Mada, Yogyakarta, Indonesia ${ }^{2,3}$

Pujonurcahyo76@gmail.com

Diterima : Januari 2016; Direvisi : Juli 2016; Dipubikasikan: September 2016

\begin{abstract}
ABSTRAK Saat ini masyarakat di beberapa daerah di Indonesia mengalami kekurangan air akibat kekeringan/krisis air yang disebabkan oleh musim kemarau yang panjang. Penyediaan air bersih di Indonesia masih sering terjadi masalah, yaitu tingkat pelayanan air minum, kualitas dan kuantitas air serta pasokan dan distribusinya. Air yang dikonsumsi oleh masyarakat terutama untuk kebutuhan domestik seperti air minum menjadi permasalahan di Indonesia. Masalah tersebut adalah kekurangan pasokan air bersih. Berkaitan dengan hal tersebut, penelitian ini dilatar belakangi seberapa besar potensi sumberdaya air digunakan untuk pemenuhan kebutuhan domestik penduduk Kecamatan Eromoko. Tujuan penelitian adalah (1) menganalisis potensi sumberdaya air Kecamatan Eromoko; (2) menganalisis kebutuhan domestik penduduk Kecamatan Eromoko; (3) melakukan evaluasi ketersediaan air terhadap kebutuhan air domestik di Kecamatan Eromoko.Data primer yang digunakan adalah data wawancara jumlah kebutuhan domestik penduduk, kedalaman muka airtanah, elevasi, kualitas air dan data debit air. Data sekunder meliputi data bor, data kontur elevasi dan data pendukung lainnya. Sampel data primer ditentukan secara sistematik, proposional dan purposif. Tujuan (1) dicapai dengan menentukan kualitas dan kuantias air. Kuantitas air didapatkan dari debit dinamis airtanah, mataair, sungai bawah tanah. Kualitas air didapatkan dari hasil uji laboratorium sampel air terhadap nilai pada peraturan mengenai kualitas air. Tujuan (2) dicapai dengan menghitung jumlah kebutuhan air untuk domestik penduduk Kecamatan Eromoko. Tujuan (3) dicapai dengan membandingkan kuantitas sumberdaya air yang tersedia dengan jumlah kebutuhan air untuk domestik penduduk Kecamatan Eromoko. Hasil penelitian diuraikan secara deskriptif kuantitatif, deskriptif kualitatif serta komparatif. Hasil penelitian meliputi (1) potensi sumberdaya air daerah penelitian memiliki nilai debit dinamis sebesar 121 juta lt/hari atau 121 juta $\mathrm{m}^{3} /$ hari dan $69 \%$ kualitas sumber air dalam kondisi baik. (2) jumlah kebutuhan air untuk domestik sebesar $6.840 .076 \mathrm{l} / \mathrm{hari}$ atau $6.840 \mathrm{~m}^{3} /$ hari. (3) potensi sumberdaya air dapat mencukupi kebutuhan domestik penduduk karena jumlah kebutuhan domestik lebih kecil daripada debit dinamis airtanah dengan kualitas air kondisi baik.
\end{abstract}

Kata kunci: kuantitas dan kualitas air; kebutuhan domestik penduduk; pengelolaan potensi sumber air.

ABSTRACT In resent time some comunities in several regions in Indonesia suffering water shortages due to drought / water crisis caused by prolonged drought. The provision of clean water in Indonesia are still common problem, namely the level of drinking water, water quality and quantity as well as supply and distribution. Water consumed by the public mainly for domestic needs such as drinking water a problem in Indonesia. The problem is the shortage of water supply. In this regard, the research background of how much potential water resources are used to meet the domestic needs of District residents Eromoko. The research objective is (1) to analyze the potential of water resources District of Eromoko; (2) analyzing domestic needs Eromoko District residents; (3) evaluating the availability of water for domestic water needs in District Eromoko. The primary data used is the interview the number of domestic needs of the population, the depth of groundwater level, elevation, water quality and water flow data. Secondary data includes drill data, elevation contour data and other supporting data. Primary data sample is determined systematically, proportional and purposive. Objectives (1) is achieved by determining the quality and the quantity of water. The quantity of water obtained from a dynamic discharge groundwater, springs, underground rivers, water quality obtained from laboratory test results of water samples against the values on the regulation of water quality. Purpose (2) is achieved by calculating the amount of water needs for domestic residents Eromoko districts. Purpose (3) is achieved by comparing the quantity of available water resources with the required amount of water for domestic residents Eromoko districts. Results of the study are described in descriptive quantitative, qualitative descriptive and comparative. Results of the study include (1) the potential of water resources research area has a value of dynamic discharge of 121 million liters /day or 121 million $\mathrm{m}^{3} /$ day and 69\% quality of water resources in good condition. (2) the amount of domestic water needs of 6.840 .076 liters/day or $6.840 \mathrm{~m}^{3} /$ day. (3) the potential of water resources can meet the domestic needs of the population because of the amount of domestic demand is smaller than the dynamic flow of groundwater to the water quality good condition.

Key words: water quantity and quality; the domestic needs of the population; management of potential sources of water.

\section{PENDAHULUAN}

Berdasarkan UU RI No. 7 Tahun 2004, air adalah semua wujud air yang terdapat di atas maupun di bawah permukaan tanah, termasuk dalam pengertian ini air permukaan, air tanah, air hujan, dan air laut yang berada di darat (tambak). Air berfungsi sebagai sumber kehidupan dan penghidupan, sekaligus melengkapi kehidupan manusia dan seluruh flora dan fauna yang ada di bumi. Air selain menopang kehidupan secara terus menerus juga membentuk suatu lingkungan dan cara hidup yang unik di sekitar sumber air.

Kehidupan manusia juga tidak akan dapat dipisahkan dari air, oleh karena itu air sebagai sumberdaya untuk memenuhi kebutuhan manusia merupakan kebutuhan yang sangat penting dan harus dipenuhi. Jumlah penduduk yang semakin bertambah, kebutuhan akan air semakin meningkat. Dalam pemenuhan kebutuhan air tidak hanya dalam 
kualitasnya tetapi berkaitan dengan kualitasnya. Konsumsi air penduduk Indonesia di masing-masing daerah tidak sama, hal ini dikarenakan oleh ketersediaan air pada masing-masing daerah sehingga akan mempengaruhi perilaku masyarakat dalam memenuhi kebutuhan air minum untuk kebutuhan rumah tangga.

Penelitian dilakukan di Kecamatan Eromoko Kabupaten Wonogiri Provinsi Jawa Tengah. Kondisi fisik Kecamatan Eromoko yang memiliki variasi bentukan asal bentuklahan akan berpengaruh terhadap potensi air yang tersimpan. Kondisi fisik daerah yang memiliki morfologi karst potensi airnya akan tersimpan dibawah permukaan bumi dan dapat menjadi sistem sungai bawah tanah. Morfologi karst yang kering di atas tapi mempunyai cadangan air yang tersimpan di bawah besar. Proses ini dipengaruhi oleh batuan karbonat yang mempunyai rongga-rongga dan mudah melarutkan air sehingga akan membentuk sistem drainase bawah permukaan. Penampungan air hujan (PAH) digunakan sebagai cadangan air yang dapat digunakan oleh masyarakat sewaktu musim kemarau selain juga mendapatkan bantuan dari truk tangki. Morfologi daerah aluvial dan struktural cadangan air yang tersedia cukup banyak karena mempunyai airtanah yang dangkal. Karakteristik yang bervariasi dan belum banyak dikaji secara luas, oleh karena itu tujuan penelitian yaitu (1) menganalisis potensi sumberdaya air Kecamatan Eromoko; (2) menganalisis kebutuhan domestik penduduk Kecamatan Eromoko; dan (3) menganalisis pengaruh ketersediaan air bersih terhadap kebutuhan air bersih domestik di Kecamatan Eromoko.

Secara administrasi daerah penelitian masuk dalam wilayah Kecamatan Eromoko Kabupaten Wonogiri yang dalam peta rupa bumi terletak pada garis lintang dan garis bujur berkisar antara $7^{\circ} 44^{\prime} 35,8^{\prime \prime} \mathrm{LS}-8^{\circ} 39^{\prime} 58^{\prime \prime} \mathrm{LS}$ dan $110^{\circ} 22^{\prime 2} 28,7^{\prime \prime}$ BT-110 $42^{\prime} 6,05^{\prime \prime}$ BT. Luas Kecamatan Eromoko adalah 12.035,85 Ha (Kecamatan Eromoko dalam Angka, 2013). Lokasi penelitian ditunjukkan pada Gambar 1.

Struktur geologi daerah penelitian menurut stratigrafinya terletak pada Formasi Semilir, Nampol/Nglanggran, Wonosari-Punung dan Baturetno dengan batuan utama berupa batu gamping dan batuan utama tuff. Berdasarkan pembagian fisiografi Bemmelen (1949), daerah penelitian termasuk rangkaian Pegunungan Selatan Jawa Timur ditunjukkan adanya sebagian daerah dengan litologi batugamping dan breksi-tuff-napal serta diperkuat lagi dengan letak fisiografis daerah penelitian diantara Gunung Panggung dan topografi karst Gunungsewu.

Kecamatan Eromoko mempunyai tipe iklim Aw yaitu suhu udara rata-rata bulan kurang dari $18^{\circ} \mathrm{C}$ dan suhu udara rata-rata tahunan $20^{\circ} \mathrm{C}-25^{\circ} \mathrm{C}$ serta mempunyai curah hujan dengan curah hujan kurang dari $60 \mathrm{~mm}$ dan curah hujan rata-rata tahunan kurang dari $2.500 \mathrm{~mm}$. Curah hujan tahunan rata-rata sebesar 1464,40 mm dengan 5 bulan kering (curah hujan $<60 \mathrm{~mm} /$ bulan) yaitu pada bulan Juni hingga Oktober, sehingga hal ini berpengaruh terhadap potensi air yang tersimpan di lokasi penelitian.

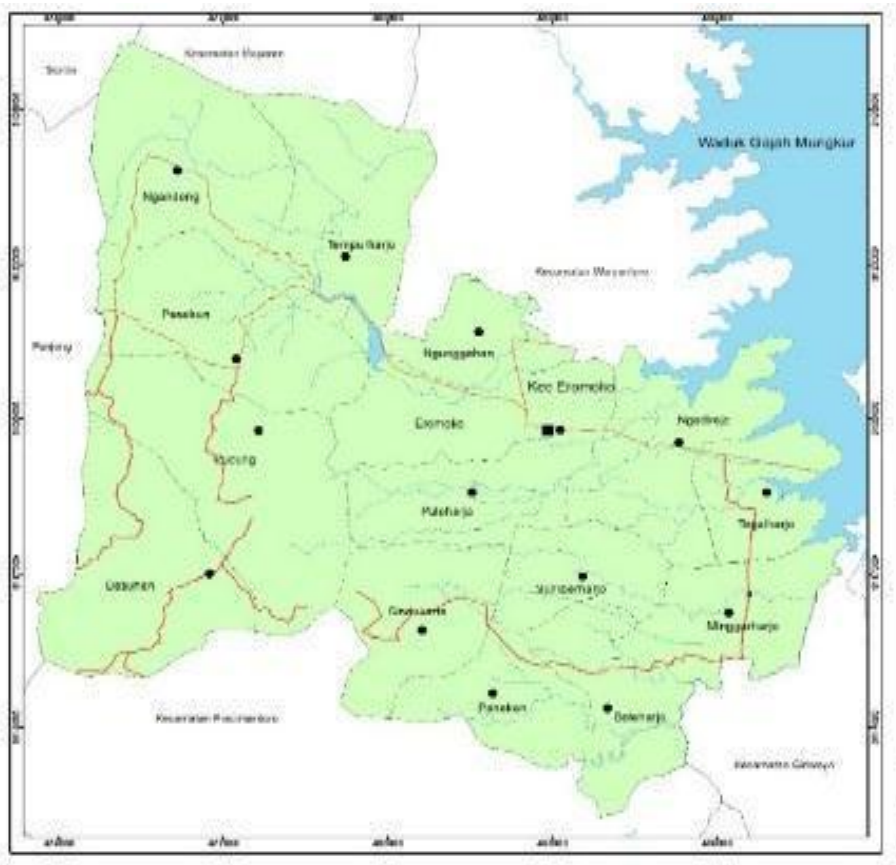

Gambar 1. Lokasi Penelitian

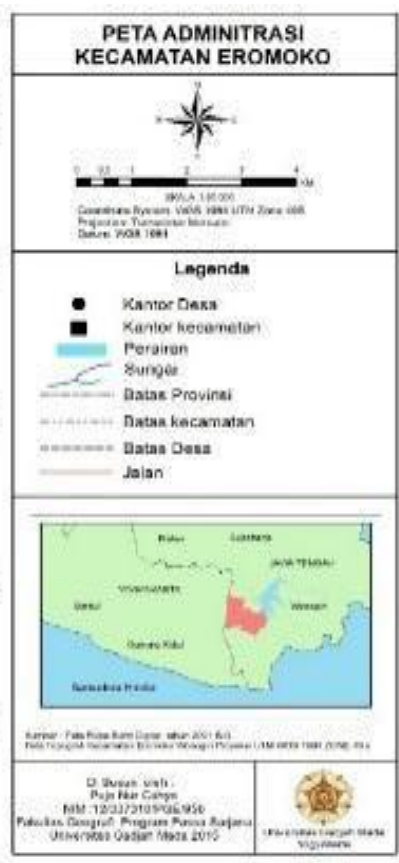

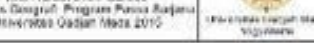




\section{METODE PENELITIAN}

Metode penelitian ini terdiri dari 3 (tiga) tahapan yaitu tahapan survei pendahuluan, tahapan pengumpulan dan pengolahan data serta tahapan perhitungan dan analisa data. Survei pendahuluan merupakan kegiatan untuk memperoleh gambaran lokasi penelitian dengan cara studi literatur mengenai potensi sumberdaya air secara umum dan ketersediaan peta-peta, data bor dan data pendukung lainnya. Pengumpulan data terdiri atas data primer dan sekunder. Data primer terdiri dari data kualitas air, data kebutuhan air domestik penduduk, data potensi sumberdaya air, sedang data sekunder yaitu data curah hujan, monografi penduduk. Pengumpulan data primer dengan wawancara menggunakan metode purposive sampling, sedangkan untuk data sekunder diperoleh dari instansi-instansi terkait. Tahapan perhitungan dan analisa data merupakan kegiatan untuk menjawab 3 (tiga) substansi tujuan yaitu menganalisis potensi sumberdaya air Kecamatan Eromoko; menganalisis kebutuhan domestik penduduk Kecamatan Eromoko; dan menganalisis ketersediaan air bersih dengan kebutuhan air bersih domestik di Kecamatan Eromoko.

Perhitungan potensi sumberdaya air kecamatan Eromoko dengan terdapat 2 macam yaitu ketersediaan potensi airtanah dinamis, ketersediaan hujan wilayah (PAH) dan ketersediaan potensi mataair. Ketersediaan potensi airtanah dinamis dengan menggunakan metode rumus Darcy (1856) dalam Todd (1980) yaitu debit airtanah dihitung dengan menggunakan rumus :

$$
Q=K \cdot A \cdot \frac{d h}{d l} \operatorname{atau} Q=K \cdot A \cdot i
$$

$$
\begin{array}{lr}
\mathrm{Q} & \text { : debit atau jumlah aliran airtanah } \\
\mathrm{K} & \text { : konduktivitas hidrolik/permeabilitas } \\
\frac{d h}{d l} \text { atau I } & \text { : gradient hidrolik/kemiringan } \\
& \text { permukaan airtanah }
\end{array}
$$

Kebutuhan air domestik merupakan kebutuhan penduduk dalam memenuhi kebutuhan sehari-hari dalam rumah tangga seperti mandi, mencuci, masak, minum, kakus (WC) dan kegiatan lain (mengepel, mencuci kendaraan, menyiram tanaman, minum ternak). Dalam memprediksi kebutuhan air untuk keperluan domestik didasarkan pada rata-rata penggunaan air bersih oleh penduduk serta jumlah penduduk. Kebutuhan rata-rata penduduk diketahui melalui data pemakaian air dari PDAM serta analisis data sekunder yang diperoleh melalui wawancara dengan cara cara proposional (Propotional Sampling) yaitu penduduk kecamatan Eromoko yang tersebar merata yang memanfaatkan sumber air yang terdapat di masing-masing desa. Responden yang diambil dalam wawancara adalah Kepala Keluarga (KK). Proses pengambilan jumlah responden untuk mengetahui jumlah Kepala Keluarga (KK) yang akan di lakukan wawancara dengan menggunakan sistem Grids atau kotak-kotak persegi imajiner dalam ukuran tertentu. Setelah Grids terbentuk, lokasi responden yang akan diwawancarai dapat diketahui (Gambar 2).

Untuk mengetahui kebutuhan air domestik penduduk dengan menggunakan rumus sebagai berikut:

$$
\text { Kebutuhan Air Domestik }=\frac{\text { Kebutuhan Air } / \text { Keluarga } / \text { Hari }}{\text { Jumlah Jiwa per Keluarga }(\text { orang })}
$$
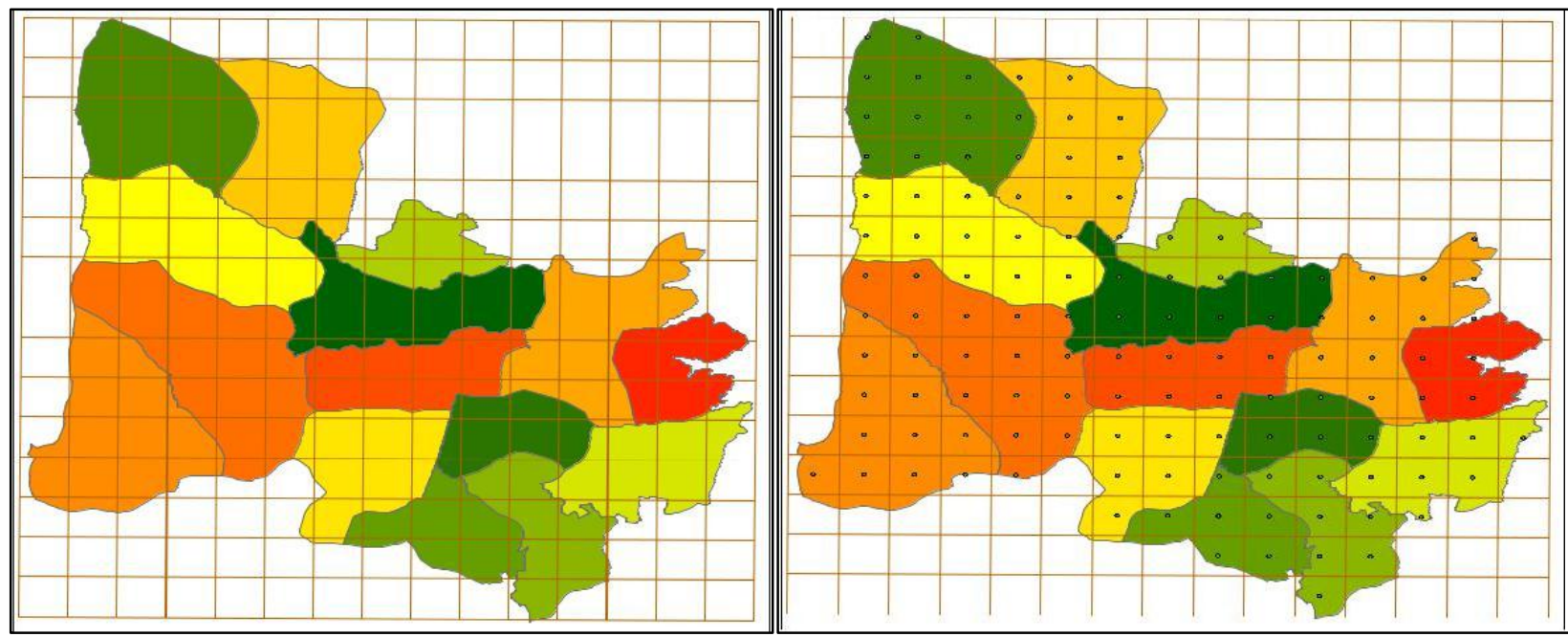

Gambar 2. Grid Imajiner Penentuan Lokasi Sampel pada Setiap Grid 
Perhitungan debit mataair dengan menggunakan metode current meter, metode volumetrik dan velocity area methods menggunakan pelampung permukaan. Pengambilan data kualitas air secara purposive sampling dengan lokasi titik sampel yang telah ditentukan. Potensi hujan wilayah rata-rata yang jatuh di lokasi penelitian dengan menggunakan metode Isohyet dengan rumus :

$$
P=\frac{1 \frac{I 1+I 2}{2}+A 2 \frac{I 2+I 3}{2}+\cdots+A n \frac{I n+I n+1}{2}}{A 1+A 2+\cdots+A n}
$$

Dimana :

$$
\begin{array}{ll}
\mathrm{P} & : \text { hujan rerata kawasan } \\
\mathrm{I} 1, \mathrm{I} 2, \ldots, \mathrm{In} & \text { : garis isohyet ke } 1,2,3, \ldots \mathrm{n} \\
\mathrm{A} 1, \mathrm{~A} 2, \ldots, \mathrm{An} & \text { : luas daerah yang dibatasi oleh garis } \\
& \text { isohyet ke } 1 \text { dan } 2,2 \text { dan } 3, \ldots, \mathrm{n} \text { dan } \\
& \mathrm{n}+1
\end{array}
$$

Penelitian ini menggunakan metode analisis deskriptif kualitatif, kuantitatif dan komparatif dimana untuk mengidentifikasi dan menggambarkan ketersediaan air didasarkan dari hasil pengukuran. Klasifikasi sampel kualitas air dianalisis secara spasial dengan menggunakan batasan unit formasi batuan. Kondisi sosial ekonomi merupakan salah satu informasi pendukung dalam memberikan informasi untuk analisa kebutuhan air domestik harian.

\section{HASIL DAN PEMBAHASAN}

Pola penggunaan sumber air yang digunakan oleh penduduk kecamatan Eromoko secara umum terdiri atas air PDAM, airtanah, mataair, air sungai bawah tanah dan Penampungan Air Hujan (PAH), seperti yang tersaji dalam Tabel 1. Ketersediaan air di wilayah kecamatan Eromoko tersebar tidak merata, hal ini disebabkan oleh kondisi struktur formasi geologi daerah penelitian sehingga berpengaruh terhadap pola konsumsi kebutuhan domestik sehari-hari. Struktur formasi geologi daerah penelitian yaitu formasi Baturetno, Semilir, Nampol dan Wonosari. Hasil yang dihitung dan analisa yaitu potensi hujan wilayah dan penampungan air hujan, kuantitas dan kualitas sumberdaya air serta kebutuhan air domestik penduduk kecamatan Eromoko.

\section{Potensi Hujan Wilayah}

Potensi curah hujan diperoleh dari perhitungan data curah hujan dari beberapa stasiun yang terdapat di dekat wilayah daerah penelitian seperti stasiun curah hujan Manyaran, Wuryantoro, Pracimantoro, Giritontro serta Eromoko. Berdasarkan kelengkapan data curah hujan selama siklus 10 (sepuluh) tahun dari tahun 2003-2012, diketahui bahwa nilai curah hujan dari masing-masing stasiun bervariasi, yaitu stasiun hujan Eromoko mempunyai nilai curah hujan sebesar $1507 \mathrm{~mm} / \mathrm{th}$, stasiun hujan Pracimantoro sebesar $1449 \mathrm{~mm} / \mathrm{th}$, stasiun hujan Wuryantoro sebesar $1655 \mathrm{~mm} / \mathrm{th}$, stasiun hujan Manyaran sebesar $1728 \mathrm{~mm} /$ th dan stasiun hujan Giritontro sebesar $2969 \mathrm{~mm} / \mathrm{th}$.

Variasi tebal hujan wilayah masing-masing desa dilakukan dengan cara metode intersect (penggabungan) data spasial peta administrasi dengan

\begin{tabular}{|c|c|c|c|c|c|c|c|c|c|}
\hline \multirow[b]{2}{*}{ No } & \multirow[b]{2}{*}{ Desa/Kel } & \multicolumn{8}{|c|}{ Penggunaan Sumber Air } \\
\hline & & $\begin{array}{c}\text { Sumur } \\
\text { (Airtanah) }\end{array}$ & Mataair & PDAM & PDAM/Sumur & Mataair/Sumur & PDAM/Mataair & $\begin{array}{c}\text { SBT Gua } \\
\text { Suruh }\end{array}$ & PAH \\
\hline 1 & Eromoko & $\sqrt{ }$ & $\sqrt{ }$ & & & & & & \\
\hline 2 & Tegalharjo & $\sqrt{ }$ & & & & & & & \\
\hline 3 & Sumberharjo & $\sqrt{ }$ & & & & & & & \\
\hline 4 & Minggarharjo & $\sqrt{ }$ & & & $\sqrt{ }$ & & & & \\
\hline 5 & Baleharjo & $\sqrt{ }$ & & & & $\sqrt{ }$ & & & \\
\hline 6 & Panekan & $\sqrt{ }$ & & & & & & & \\
\hline 7 & Sindukarto & & $\sqrt{ }$ & $\sqrt{ }$ & & $\sqrt{ }$ & $\sqrt{ }$ & & \\
\hline 8 & Ngunggahan & $\sqrt{ }$ & & & & & & & \\
\hline 9 & Tempurharjo & $\sqrt{ }$ & $\sqrt{ }$ & & & $\sqrt{ }$ & & & \\
\hline 10 & Ngandong & $\sqrt{ }$ & $\sqrt{ }$ & & & & & & \\
\hline 11 & Pasekan & $\sqrt{ }$ & $\sqrt{ }$ & $\sqrt{ }$ & & & & & \\
\hline 12 & Pucung & $\sqrt{ }$ & $\sqrt{ }$ & $\sqrt{ }$ & & $\sqrt{ }$ & & $\sqrt{ }$ & $\sqrt{ }$ \\
\hline 13 & Basuhan & $\sqrt{ }$ & $\sqrt{ }$ & & & & & & $\sqrt{ }$ \\
\hline 14 & Ngadirejo & $\sqrt{ }$ & & & $\sqrt{ }$ & & & & \\
\hline 15 & Puloharjo & & & $\sqrt{ }$ & $\sqrt{ }$ & & & & \\
\hline
\end{tabular}
data spasial Isohyet dengan menggunakan perangkat lunak komputer software Arcgis 10.2.2. Hasil dan distribusi hujan wilayah lokasi penelitian seperti tersaji dalam Tabel 2.

Tabel 1. Pola Penggunaan Sumber Air per Desa/Kelurahan di Kecamatan Eromoko

Sumber : Hasil Wawancara dan Kunjungan Lapangan (2015) 
Tabel 2. Distribusi Hujan Wilayah Lokasi Penelitian

\begin{tabular}{clccc}
\hline No & Desa/kelurahan & Luas Wilayah $\left(\mathrm{m}^{2}\right)$ & Tebal Hujan Tahunan $(\mathrm{mm} /$ tahun $)$ & Volume Hujan Tahunan $\left(\mathrm{m}^{3} /\right.$ tahun $)$ \\
\hline 1 & Eromoko & 684.46 & 1.569 & 10.739 .177 \\
2 & Tegalharjo & 884.14 & 1.723 & 15.233 .732 \\
3 & Sumberharjo & 420.97 & 1.701 & 7.160 .699 \\
4 & Minggarharjo & 645.37 & 1.878 & 12.120 .048 \\
5 & Baleharjo & 555.7 & 2.035 & 11.308 .495 \\
6 & Panekan & 498.33 & 1.925 & 9.592 .852 \\
7 & Sindukarto & 584.24 & 1.747 & 10.206 .672 \\
8 & Ngunggahan & 669.26 & 1.577 & 10.554 .230 \\
9 & Tempurharjo & 919.7 & 1.644 & 15.119 .868 \\
10 & Pasekan & 102.67 & 1.652 & 16.961 .084 \\
11 & Ngadirejo & 821.36 & 1.622 & 13.322 .459 \\
12 & Puloharjo & 504.9 & 1.593 & 8.043 .057 \\
13 & Ngandong & 944.69 & 1.604 & 15.152 .827 \\
14 & Pucung & 1.732 .160 & 1.702 & 29.481 .363 \\
15 & Basuhan & 1.143 .890 & 1.746 & 19.972 .319 \\
\hline
\end{tabular}

Sumber : Hasil Analisa Data Sekunder (2015)

Berdasarkan hasil Tabel 2 tersebut diatas, rata-rata hujan wilayah daerah penelitian sebesar 1.714 $\mathrm{mm}$ /tahun. Selanjutnya, untuk menghitung banyaknya air yang efisien dan potensi untuk dapat dimanfaatkan, tidak semua air hujan yang jatuh dapat dimanfaatkan sebagai potensi air hujan, karena membutuhkan media untuk penangkap air dan menyimpan air hujan berupa $\mathrm{PAH}$ atau bangunan penampung air hujan. Banyaknya hujan tahunan yang bisa ditangkap yaitu dengan menghitung hasil perkalian antara luas atap yang memungkinkan dapat menangkap air hujan $\left(\mathrm{m}^{2}\right)$, jumlah kepala keluarga (KK) tiap desa serta tebal hujan yang jatuh di desa tersebut (m/tahun). Luas atap yang digunakan sebagai penangkap hujan di daerah penelitian menggunakan asumsi dengan kira-kira luas atap adalah $50 \mathrm{~m}^{2} /$ rumah tangga (KK). Hasil analisis data potensi penampungan air hujan (PAH) daerah penelitian seperti tersaji dalam Tabel 3.

Desa Basuhan dan Pucung merupakan 2 (dua) desa yang pada saat musim hujan banyak penduduk memanen air hujan. Hal ini dilakukan sebagai cara untuk mendapatkan sumber air. Desa Basuhan dan Pucung merupakan desa di kecamatan Eromoko yang masuk dalam kawasan karst sehingga banyak memanfaatkan penampungan air hujan untuk menyimpan air dikala sulit mendapatkan air. Jumlah data PAH menurut data monografi kecamatan Eromoko Tahun 2013, untuk Desa Basuhan berjumlah 691 unit dengan jumlah KK 1.011 dan Desa Pucung berjumlah 850 unit dengan jumlah KK 1.440, sehingga persebaran $\mathrm{PAH}$ yang terdapat di kawasan Karst lokasi penelitian berjumlah 1.541 buah dan mampu untuk mencukupi $62 \%$ dari $2.451 \mathrm{KK}$.
Berdasarkan hasil tabel tersebut diatas, rata-rata hujan wilayah daerah penelitian sebesar 1.714 $\mathrm{mm} /$ tahun. Selanjutnya, untuk menghitung banyaknya air yang efisien dan potensi untuk dapat dimanfaatkan, tidak semua air hujan yang jatuh dapat dimanfaatkan sebagai potensi air hujan, karena membutuhkan media untuk penangkap air dan menyimpan air hujan berupa PAH atau bangunan penampung air hujan. Banyaknya hujan tahunan yang bisa ditangkap yaitu dengan menghitung hasil perkalian antara luas atap yang memungkinkan dapat menangkap air hujan $\left(\mathrm{m}^{2}\right)$, jumlah kepala keluarga (KK) tiap desa serta tebal hujan yang jatuh di desa tersebut (m/tahun). Luas atap yang digunakan sebagai penangkap hujan di daerah penelitian menggunakan asumsi dengan kira-kira luas atap adalah $50 \mathrm{~m}^{2} /$ rumah tangga (KK). Hasil analisis data potensi penampungan air hujan (PAH) daerah penelitian seperti tersaji dalam Tabel 3.

Desa Basuhan dan Pucung merupakan 2 (dua) desa yang pada saat musim hujan banyak penduduk memanen air hujan. Hal ini dilakukan sebagai cara untuk mendapatkan sumber air. Desa Basuhan dan Pucung merupakan desa di kecamatan Eromoko yang masuk dalam kawasan karst sehingga banyak memanfaatkan penampungan air hujan untuk menyimpan air dikala sulit mendapatkan air. Jumlah data PAH menurut data monografi kecamatan Eromoko Tahun 2013, untuk Desa Basuhan berjumlah 691 unit dengan jumlah KK 1.011 dan Desa Pucung berjumlah 850 unit dengan jumlah KK 1.440, sehingga persebaran PAH yang terdapat di kawasan Karst lokasi penelitian berjumlah 1.541 buah dan mampu untuk mencukupi $62 \%$ dari $2.451 \mathrm{KK}$. 
Tabel 3. Jumlah Potensi Hujan Tertangkap di Kecamatan Eromoko

\begin{tabular}{|c|c|c|c|c|c|c|c|}
\hline No & Desa/kelurahan & $\begin{array}{l}\text { Luas Wilayah } \\
\qquad\left(\mathrm{m}^{2}\right)\end{array}$ & $\begin{array}{l}\text { Tebal Hujan Tahunan } \\
\text { (mm/tahun) }\end{array}$ & $\begin{array}{l}\text { Jumlah } \\
\text { KK }\end{array}$ & $\begin{array}{l}\text { Luas Atap/KK } \\
\left(\mathrm{m}^{2}\right)\end{array}$ & $\begin{array}{c}\text { Luas atap } \mathrm{x} \\
\mathrm{KK}\left(\mathrm{m}^{2} / \mathrm{desa}\right)\end{array}$ & $\begin{array}{c}\text { Hujan Tertangkap } \\
\left(\mathrm{m}^{3} / \text { tahun }\right)\end{array}$ \\
\hline 1 & Eromoko & 684.46 & 1.569 & 1.687 & 50 & 84.366 & 132.370 .494 \\
\hline 2 & Tegalharjo & 884.14 & 1.723 & 555 & 50 & 27.763 & 47.835 .773 \\
\hline 3 & Sumberharjo & 420.97 & 1.701 & 788 & 50 & 39.409 & 67.034 .019 \\
\hline 4 & Minggarharjo & 645.37 & 1.878 & 1.178 & 50 & 58.921 & 110.654 .077 \\
\hline 5 & Baleharjo & 555.7 & 2.035 & 970 & 50 & 48.48 & 98.657 .655 \\
\hline 6 & Panekan & 498.33 & 1.925 & 958 & 50 & 47.878 & 92.165 .276 \\
\hline 7 & Sindukarto & 584.24 & 1.747 & 820 & 50 & 40.978 & 71.589 .207 \\
\hline 8 & Ngunggahan & 669.26 & 1.577 & 868 & 50 & 43.424 & 68.480 .108 \\
\hline 9 & Tempurharjo & 919.7 & 1.644 & 1.176 & 50 & 58.793 & 96.656 .450 \\
\hline 10 & Pasekan & 102.67 & 1.652 & 1.039 & 50 & 51.949 & 85.818 .959 \\
\hline 11 & Ngadirejo & 821.36 & 1.622 & 1.393 & 50 & 69.636 & 112.949 .340 \\
\hline 12 & Puloharjo & 504.9 & 1.593 & 1.372 & 50 & 68.595 & 109.272 .494 \\
\hline 13 & Ngandong & 944.69 & 1.604 & 1.055 & 50 & 52.733 & 84.584 .388 \\
\hline 14 & Pucung & 1.732 .160 & 1.702 & 1.44 & 50 & 72.009 & 122.558 .904 \\
\hline 15 & Basuhan & 1.143 .890 & 1.746 & 1.011 & 50 & 50.543 & 88.248 .128 \\
\hline
\end{tabular}

Sumber : Kecamatan Eromoko dalam Angka 2013 dan Analisa Data Sekunder (2015)

\section{Potensi Airtanah Dinamis}

Potensi sumberdaya air suatu daerah tentu saja tidak lepas dari potensi airtanah yang tersimpan di daerah tersebut. Setidaknya ada dua cara dalam mengetahui kuantitas potensi airtanah pada suatu daerah, yaitu penentuan potensi airtanah secara statis dan dinamis. Potensi airtanah yang dihitung merupakan airtanah pada akuifer bebas. Perhitungan potensi airtanah menggunakan metode perhitungan debit airtanah dinamis. Penentuan airtanah dengan cara dinamis dilakukan dengan mempertimbangkan Hukum Darcy (1856) dalam Todd (1980), yang menyatakan pergerakan air yang melalui material lulus air dipengaruhi oleh konduktivitas dan gradien hidroliknya.

Penentuan potensi dibagi berdasarkan formasi geologi yang ada di daerah kajian. Terdapat setidaknya 4 formasi geologi pada daerah kajian, yaitu Formasi Semilir, Formasi Baturetno, Formasi Nampol dan Formasi Wonosoari. Formasi Wonosari merupakan formasi geologi dengan susunan dari batuan karbonat, sehingga untuk area dengan formasi geologi yang merupakan akuifer batuan karbonat potensi airtanah diukur dengan menggunakan pengukuran volumetrik ataupun velocity method. Hal tersebut disebabkan karena perhitungan menggunakan Metode Darcy hanya dapat berlaku pada akuifer yang memiliki sifat heterogen dan isotropis. Sedangkan, untuk batuan karbonat akuifer yang berkembang merupakan akuifer dengan karakter heterogen dan anisotropis.

Penentuan potensi airtanah dengan metode perhitungan airtanah dinamis setidaknya memerlukan beberapa parameter, yaitu gradien hidrolik, permeabilitas material dan luas penampang aliran. Gradien hidrolik atau kemiringan aliran pada airtanah ini dapat diketahui dengan pendekatan dari adanya pembuatan kontur airtanah. Maka dari itu, penelitian ini juga melakukan pengukuran tinggi muka airtanah (TMA) di daerah kajian. Pengukuran dilakukan pada sumur gali yang tersebar di daerah kajian kecuali daerah dengan kondisi geologi berupa batuan karbonat. Hal tersebut dilakukan dengan pertimbangan kondisi lapangan, bahwa pada Formasi Wonosari hampir tidak diketemukan adanya sumur gali. Hasil pengukuran TMA di Kecamatan menjadi dasar untuk melakukan interpolasi antar titik pengukuran yang menghasilkan peta kontur airtanah (Gambar 3). Peta kontur airtanah ini kemudian diturunkan menjadi peta arah aliran airtanah (flownet) Kecamatan Eromoko (Gambar 4).

Flownet ini selanjutnya yang akan membantu perhitungan potensi airtanah secara dinamis, karena dalam peta flownet terdapat informasi yang digunakan dalam penentuan debit airtanah secara dinamis. Perhitungan debit aliran airtanah menggunakan metode dinamis dapat dilakukan dengan melihat pola aliran airtanah. Dimana pada setiap blok aliran airtanah (Flownet) dapat dihitung debit airtanahnya dengan menentukan gradien hidrolik aliran airtanah dan penampang aliran airtanahnya. Setidaknya untuk Formasi Semilir dan Formasi Nampol terdapat 3 blok arah aliran airtanah yang digunakan untuk menentukan parameter luas penampang (A) aliran airtanah. Sedangkan untuk Formasi Baturetno luas penampang aliran airtanah ditentukan dari 1 blok arah aliran, yaitu sepanjang batas formasi sisi barat.

Metode Darcy memerlukan setidaknya 3 parameter untuk dapat menentukan debit aliran airtanah, yaitu permeabilitas (K), gradien hidrolik (I), dan luas penampang aliran (A). Dua parameter penampang aliran (A) dan gradien hidrolik (I) sudah didapatkan 
dari informasi peta flownet daerah kajian, sedangkan untuk parameter permeabilitas material (K) diketahui dengan melakukan pumping test dengan menggunakan metode slug test yang dilakukan pada 3 formasi, yaitu Formasi Semilir, Formasi Baturetno dan Formasi Nampol. Gambar 5 merupakan kegiatan uji pompa yang dilakukan di lapangan untuk mendapatkan nilai $\mathrm{K}$ setiap formasi batuan. Hasil perhitungan dari ketiga parameter tersebut yang merupakan debit aliran airtanah kemudian dinyatakan sebagai potensi airtanah dinamis dalam satuan $\mathrm{m}^{3} /$ tahun. Hasil perhitungan dapat dilihat pada Tabel 4 .

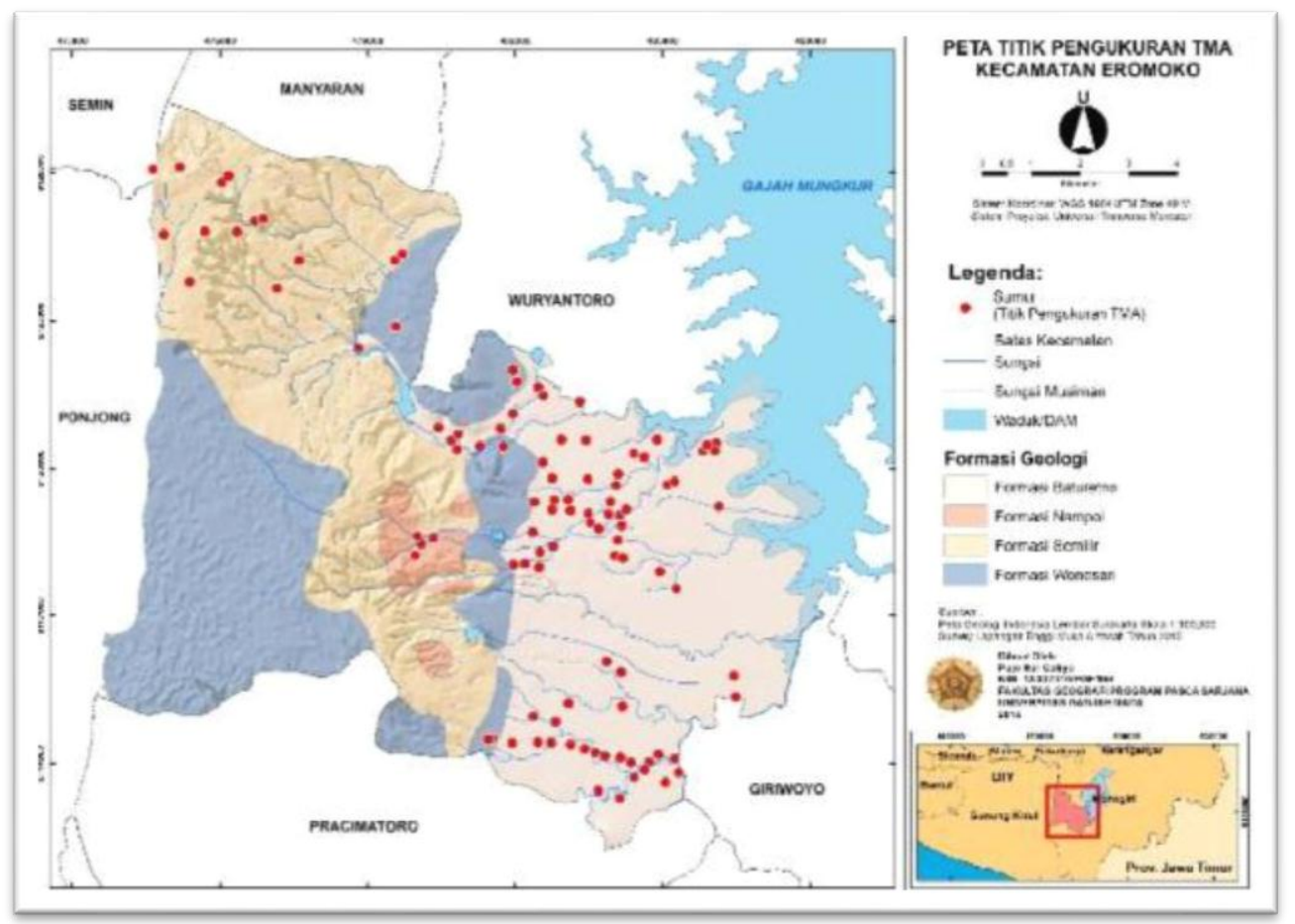

Gambar 3. Titik Sebaran Pengukuran TMA Kecamatan Eromoko Sumber : Analisi Data Lapangan (2015)

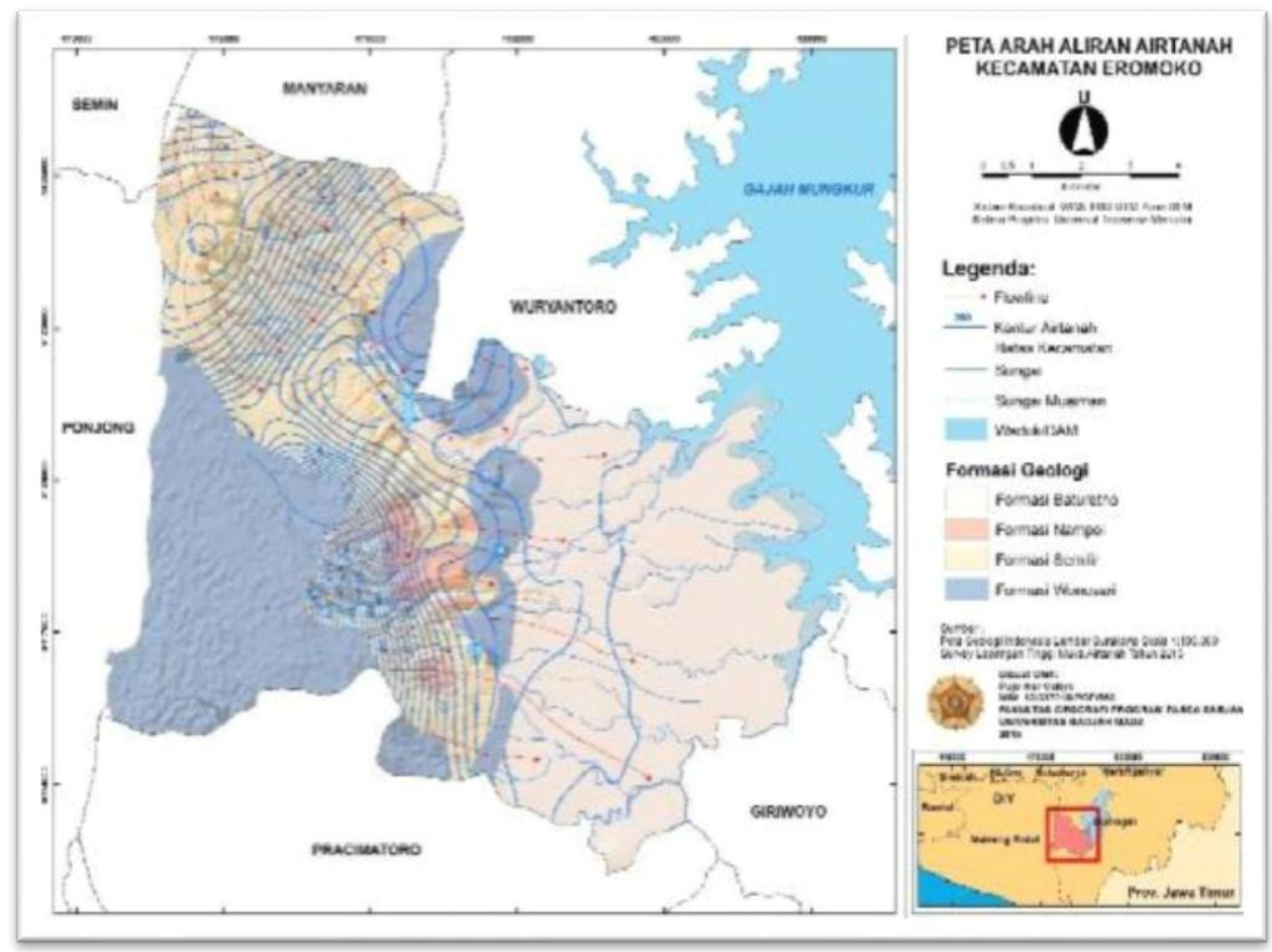

Gambar 4. Peta Arahan Aliran Airtanah Kecamatan Eromoko Sumber : Analisi Data Lapangan (2015) 

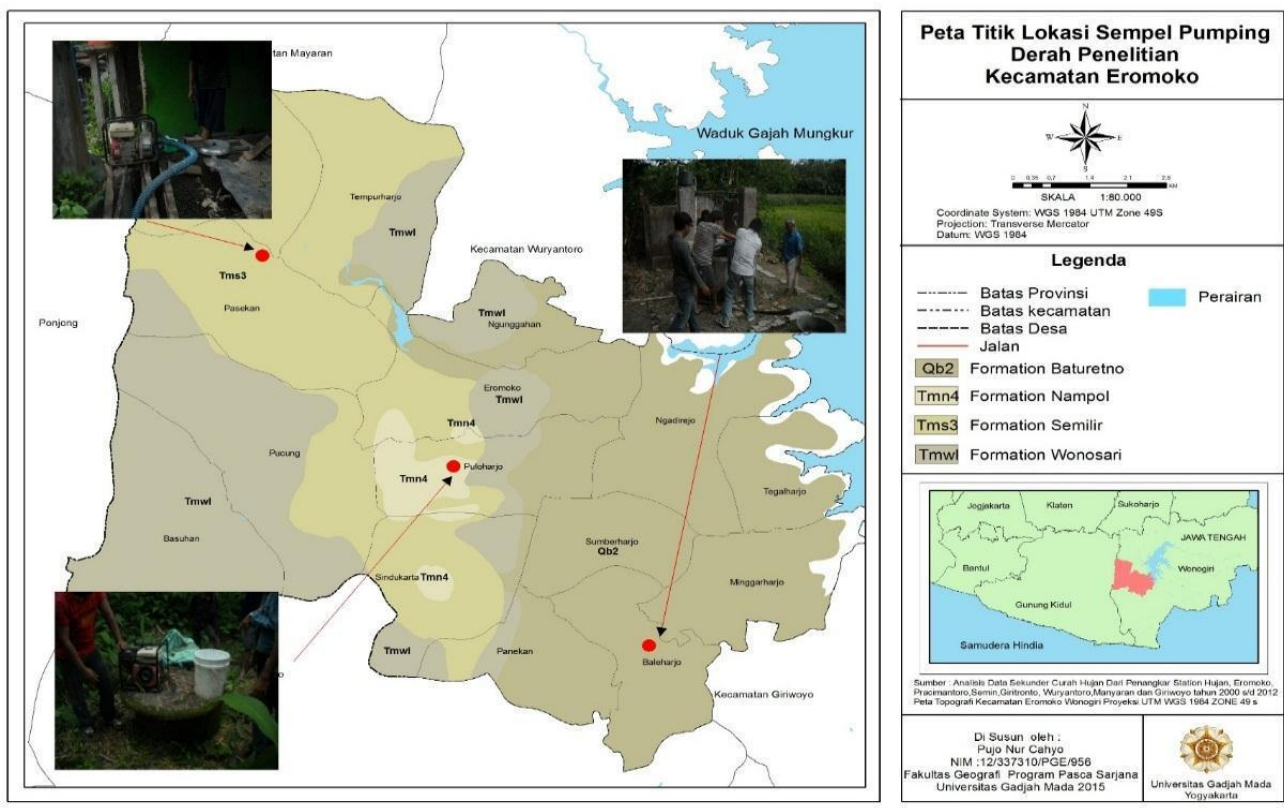

Gambar 5. Uji Pompa dengan Metode Slug Test di 3 Titik Sumur pada 3 Formasi Geologi Daerah Kajian

Tabel 4. Besar Potensi Airtanag Dinamis Akuifer Bebas Kecamatan Eromoko

\begin{tabular}{|c|c|c|c|c|c|c|}
\hline $\begin{array}{l}\text { Formasi } \\
\text { Geologi }\end{array}$ & $\begin{array}{c}\text { Luas Formasi } \\
\text { Geologi } \\
\left(\mathrm{m}^{2}\right)\end{array}$ & $\begin{array}{c}\text { Tebal Akuifer } \\
\text { Bebas } \\
(\mathrm{m})\end{array}$ & $\begin{array}{c}\text { Konduktivitas } \\
\text { Hidrolik (K) } \\
(\mathrm{m} / \text { hari }) \\
\end{array}$ & $\begin{array}{c}\text { Gradient } \\
\text { Hidrolik (I) }\end{array}$ & $\begin{array}{c}\text { Luas } \\
\text { Penampang (A) } \\
\mathrm{m}^{2} \\
\end{array}$ & $\begin{array}{c}\text { Potensi Airtanah } \\
\text { Dinamis (Metode } \\
\text { Darcy) } \mathrm{m}^{3} / \text { hari }\end{array}$ \\
\hline $\begin{array}{c}\text { Formasi } \\
\text { Baturetno }\end{array}$ & 41717944,86 & 3,1 & 3,193 & 0,010 & 36080,80 & $1,100,371$ \\
\hline $\begin{array}{l}\text { Formasi } \\
\text { Semilir }\end{array}$ & 39375513,11 & 15 & 5,881 & 0,145 & $\begin{array}{c}15708,07 \\
64303,70 \\
120533,52\end{array}$ & 120817357,18 \\
\hline $\begin{array}{l}\text { Formasi } \\
\text { Nampol }\end{array}$ & 3223900,56 & $\begin{array}{c}\text { Tidak ada } \\
\text { data }\end{array}$ & 0,4426 & 0,101 & $\begin{array}{l}\text { Tidak ada data } \\
\text { Tidak ada data } \\
\text { Tidak ada data }\end{array}$ & Tidak ada data \\
\hline $\begin{array}{c}\text { Formasi } \\
\text { Wonosari }\end{array}$ & 8944315,83 & Karbonat & Karbonat & Karbonat & Karbonat & 388,8 \\
\hline Jumlah & 93261674,35 & & & & & \\
\hline
\end{tabular}

Sumber : Analisis Data (2015)

\section{Kualitas dan Kuantitas Sumberdaya Air}

Kualitas air secara umum menunjukkan mutu atau kondisi air yang dikaitkan dengan suatu kegiatan atau keperluan tertentu. Sedangkan kuantitas menyangkut jumlah air yang dibutuhkan manusia dalam kegiatan tertentu. Air bersih dibutuhkan dalam pemenuhan kebutuhan manusia untuk melakukan segala kegiatan.

Ditinjau dari segi kualitas, ada bebarapa persyaratan yang harus dipenuhi, di antaranya sifat fisik yang terdiri atas bau, warna, rasa, kekeruhan, TDS, temperatur dan DHL, sifat kimia yang terdiri atas $\mathrm{Fe}$, CaCO3, Cl-, Mn, NO3-, NO2-, dan kesadahan, serta sifat biologi di mana air terbebas dari mikroorganisme penyebab penyakit. Kualitas air daerah penelitian (Tabel 5 dan Gambar 6) menunjukan kondisi baik walaupun terdapat beberapa parameter yang mempunyai nilai lebih dari standar baku mutu air yang dikeluarkan oleh Kementerian Kesehatan No. 492/Menkes/Per/IV/2010 tentang Persyaratan Kualitas Air Minum. Kuantitas sumberdaya air mempunyai potensi yang cukup besar dalam hal ini potensi sumber airtanah. Terdapat juga potensi lain seperti mataair dan air sungai bawah tanah Gua Suruh.

Tabel 5. Nilai Klasifikasi Faktor Pembatas Kualitas Air

\begin{tabular}{ccc}
\hline Faktor Pembatas & Jumlah & Klasifikasi \\
\hline$<8$ & 11 & Baik \\
$8-14$ & 3 & Sedang \\
$>14$ & 2 & Buruk \\
\hline
\end{tabular}

Sumber : Analisa Data (2015)

\section{Kebutuhan Air Domestik}

Kebutuhan air untuk domestik dalam penelitian ini yaitu air yang digunakan untuk sejumlah kebutuhan sehari-hari seperti untuk mandi, minum, memasak, mencuci, kakus dan kebutuhan lain. Kebutuhan air domestik daerah penelitian dilakukan dengan cara 
wawancara. Jumlah responden yang diwawancara sebanyak 126 orang yang tersebar di 15 desa/kelurahan yang menggunakan sistem proposional dengan menggunakan metode grids atau kotak-kotak imajiner untuk tiap jumlah KK. Hasil pengolahan data wawancara mengenai kebutuhan air domestik rata-rata harian per keluarga per-KK. Hasil wawancara dan analisa kebutuhan air domestik rata-rata tersaji dalam Tabel 6 dan Gambar 7.

Tabel 6. Kebutuhan Air Domestik Rata-Rata

\begin{tabular}{|c|c|c|c|c|c|c|c|c|}
\hline \multirow{2}{*}{ No } & \multirow{2}{*}{ Desa/Kel } & Masak & Minum & Mandi & Mencuci & Kakus & Lainnya & Kebutuhan Domestik \\
\hline & & \multicolumn{7}{|c|}{ (liter/orang/hari) } \\
\hline 1 & Eromoko & 1 & 2 & 58 & 2 & 10 & 9 & 82 \\
\hline 2 & Tegalharjo & 4 & 1 & 116 & 4 & 31 & 61 & 217 \\
\hline 3 & Sumberharjo & 4 & 1 & 143 & 4 & 34 & 142 & 328 \\
\hline 4 & Minggarharjo & 5 & 1 & 66 & 6 & 17 & 67 & 162 \\
\hline 5 & Baleharjo & 2 & 2 & 103 & 3 & 10 & 20 & 140 \\
\hline 6 & Panekan & 4 & 1 & 112 & 9 & 17 & 55 & 198 \\
\hline 7 & Sindukarto & 4 & 1 & 70 & 4 & 12 & 38 & 129 \\
\hline 8 & Ngunggahan & 2 & 1 & 79 & 5 & 24 & 12 & 123 \\
\hline 9 & Tempurharjo & 4 & 2 & 124 & 8 & 33 & 44 & 215 \\
\hline 10 & Ngandong & 4 & 1 & 55 & 3 & 28 & 8 & 99 \\
\hline 11 & Pasekan & 4 & 1 & 71 & 8 & 17 & 28 & 129 \\
\hline 12 & Pucung & 4 & 1 & 65 & 3 & 11 & 44 & 128 \\
\hline 13 & Basuhan & 5 & 1 & 121 & 1 & 17 & 21 & 166 \\
\hline 14 & Kel.Ngadirejo & 4 & 2 & 86 & 4 & 18 & 44 & 158 \\
\hline 15 & Kel.Puloharjo & 12 & 3 & 64 & 6 & 23 & 28 & 136 \\
\hline
\end{tabular}

Sumber : Hasil Wawancara dan Kunjungan Lapangan (2015)

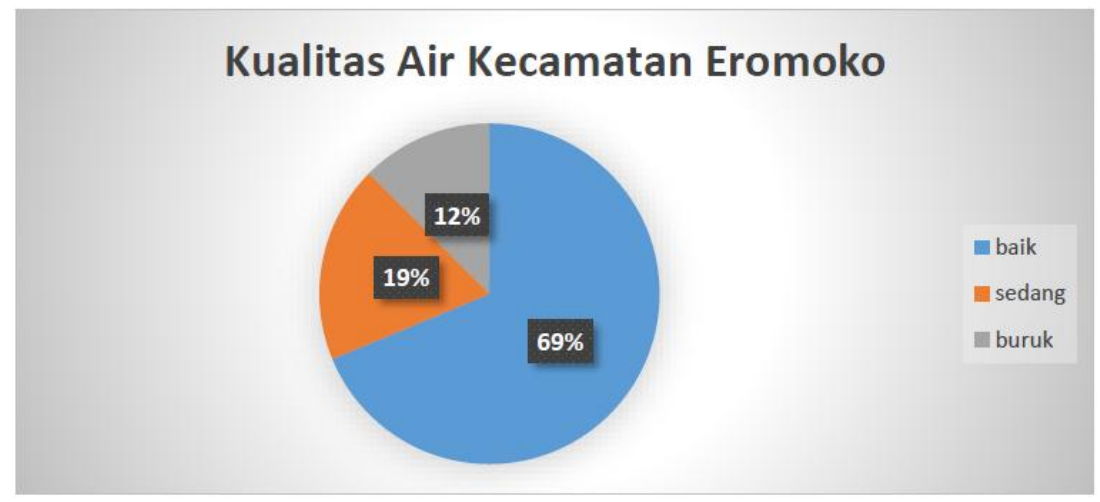

Gambar 6. Diagram Kualitas Air Kecamatan Eromoko

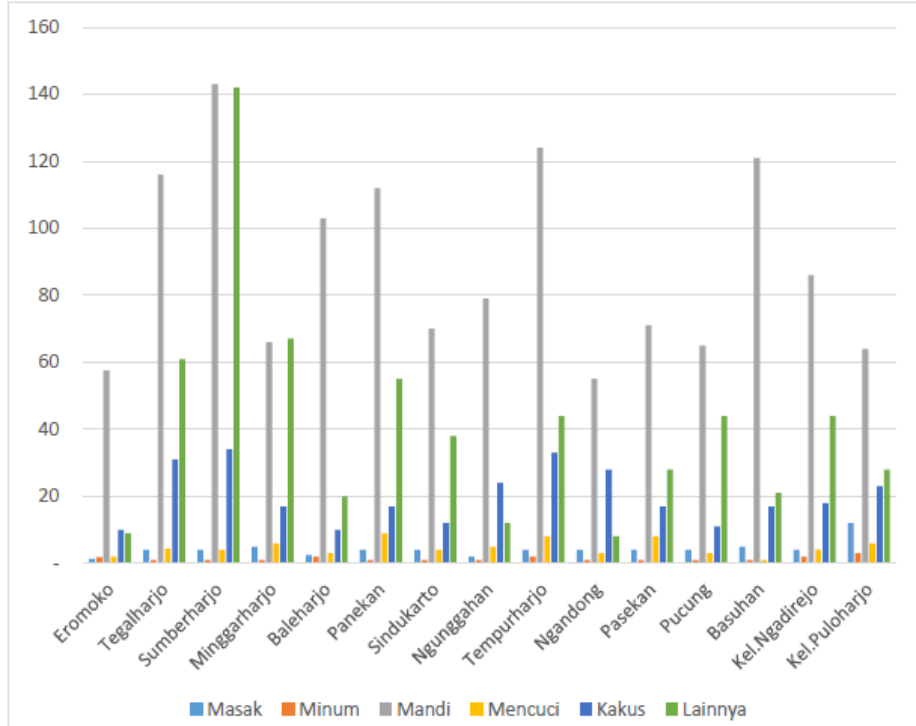

Gambar 7. Grafik Perbandingan Kebutuhan Domestik Rata-Rata Penduduk per Desa Kecamatan Eromoko 
Hasil analisis dari data wawancara kebutuhan domestik menunjukan bahwa kebutuhan air untuk domestik yang dominan adalah mandi, kebutuhan lainnya, kakus, masak, mencuci dan minum (Gambar 8). Kebutuhan domestik untuk mandi paling banyak digunakan penduduk Desa Sumberharjo yaitu 143 ltr/keluarga/hari, kebutuhan lainnya paling banyak di Desa Sumberharjo yaitu 142 ltr/keluarga/hari, kakus di Desa Sumberharjo yaitu 34 ltr/keluarga/hari, masak di Desa Puloharjo yaitu 12 ltr/keluarga/hari, mencuci di Desa Panekan yaitu 9 ltr/keluarga/hari dan minum di Desa Puloharjo yaitu 3 ltr/keluarga/hari. Berdasarkan Standar Nasional Indonesia (SNI) 19-6728.1-2002 tahun 2002 tentang sumberdaya air, penduduk kota untuk konsumsi air membutuhkan 120 ltr/hari/kapita sedangkan penduduk pedesaan memerlukan 60 ltr/hari/kapita.

\section{Potensi Sumberdaya Air untuk Mencukupi Kebutuhan Domestik}

Ketersediaan sumber daya air dapat dilihat dari besarnya kuantitas air yang dinyatakan dengan debit air dan kualitas air yang terdapat di daerah penelitian dengan melihat dari sifat fisik, kimia dan biologi air. Potensi sumber air daerah penelitian dikatakan cukup untuk memenuhi kebutuhan domestik dilihat dari debit sumber air minimal sama atau lebih dari jumlah kebutuhan domestik serta dengan kualitas sumber air yang masuk dalam klasifikasi sedang.

Perhitungan dari data pengukuran di lapangan menunjukkan potensi sumber air yang tersimpan di kecamatan Eromoko sebesar $120.818 .846 \mathrm{~m}^{3} /$ hari atau 44.098.878.918 $\mathrm{m}^{3} /$ tahun, sementara itu kebutuhan air domestik penduduk sebesar $6.840 \mathrm{~m}^{3} /$ hari atau $2.496 .768 \mathrm{~m}^{3} /$ tahun. Berdasarkan perbandingan hasil diketahui bahwa debit sumber air daerah penelitian lebih besar dari total kebutuhan air domestik penduduk. Namun terdapat 2 (dua) desa yang mempunyai potensi sumber air yang sedikit untuk memenuhi kebutuhan domestik yang disebabkan kondisi fisik desa tersebut.

Potensi sumber air daerah penelitian untuk memenuhi kebutuhan air domestik memperhatikan juga kualitas air hasil uji laboratorium. Berdasarkan baku mutu air untuk pemenuhan kebutuhan domestik, didapatkan bahwa sumber air dapat digunakan untuk mencukupi kebutuhan domestik sesuai hasil uji parameter yang dihasilkan. Namun terdapat factor pembatas yang perlu diperhatikan dalam mengkonsumsi air.

\section{KESIMPULAN}

Potensi sumberdaya air daerah penelitian didapatkan sebesar $120.818 .846 \mathrm{~m}^{3} /$ hari dan digunakan penduduk untuk memasak, minum, mandi, mencuci, kakus dan kebutuhan lainnya sebesar $6.840 \mathrm{~m}^{3} /$ hari. Penggunaan sumber air yang paling banyak adalah untuk mandi, kebutuhan lainnya, kakus, masak, mencuci dan minum. Melihat potensi debit airtanah dan kebutuhan domestik penduduk diperoleh hasil bahwa nilai potensi debit airtanah lebih besar dari jumlah kebutuhan domestic penduduk, sehingga dalam hal ini secara kuantitas sumberdaya airtanah mencukupi kebutuhan domestik penduduk. Hasil uji laboratorium untuk bau, rasa, warna, suhu, TDS, DHL, kekeruhan, Fe, $\mathrm{CaCO} 3, \mathrm{Cl}-, \mathrm{Mn}, \mathrm{NO} 3-, \mathrm{NO} 2-, \mathrm{KMnO} 4$ dan bakteri koli dalam kondisi kualitas air dalam keadaan baik sebesar $69 \%$ (dari total 9 sampel) dengan faktor pembatas yang dominan adalah bakteri koli.

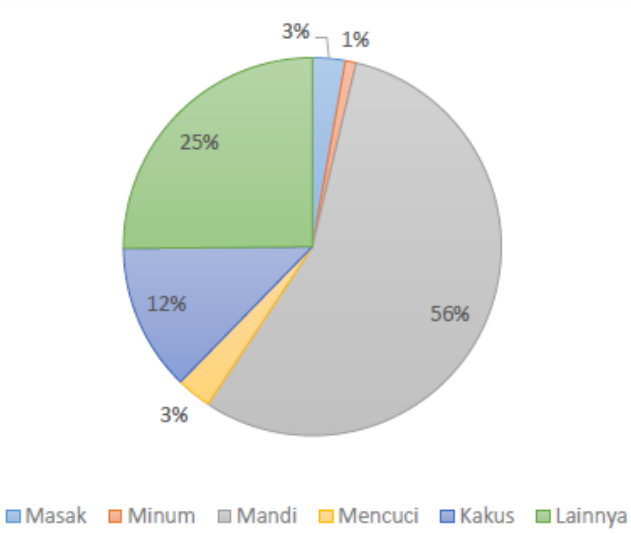

Gambar 8. Persentase Penggunaan Sumber Air untuk Kebutuhan Air Domestik 


\section{DAFTAR PUSTAKA}

Adji, T. N. (2013). Kondisi daerah tangkapan sungai bawah tanah Karst Gunungsewu dan kemungkinan dampak lingkungannya terhadap sumberdaya air (hidrologis) karena aktivitas manusia. dalam Sudarmadji, dkk (editor). 2013. Ekologi Lingkungan Kawasan Karst Indonesia: Menjaga asa kelestarian kawasan karst Indonesia. Yogyakarta : Deepublish.

Badan Standardisasi Nasional. (2002). Penyusunan Neraca Sumber Daya Bagian 1: Sumberdaya air spasial. Standar Nasional Indonesia, SNI 19-6728.12002.

Bammelen, R.W.V. (1949). The Geology of Indonesia Vol I. Government Printing Office, The Hague.

Departemen Pekerjaan Umum. (1996). Kriteria Kebutuhan Air Baku. Jakarta: Direktorat Jenderal, Cipta Karya, Departemen Pekerjaan Umum.

Fatchurohman H, Cahyadi A, Nugraha H, Wacana D. (2013). Strategi adaptasi masyarakat terhadap bencana kekeringan di kawasan karst Kecamatan Panggang, Kabupaten Gunungkidul, dalam Sudarmadji, dkk (editor). 2013. Ekologi Lingkungan Kawasan Karst Indonesia: Menjaga asa kelestarian kawasan karst Indonesia. Yogyakarta : Deepublish.

Haryono. (2011). Kekeringan di lumbung air. Ekspedisi Geografi Indonesia Karst Gunungsewu 2011. Cibinong : Pusat Survei Sumberdaya Alam Darat (PSSAD), Bakosurtanal, halaman : 24-27.

Jauhari, A. (2002). Pendugaan Sistem Sungai Bawah Tanah Melalui Pendekatan Interpretasi Morfologi Dan Survei Speleologi di Kawasan Karst Desa Pucung Kecamatan Eromoko, Kabupaten Wonogiri. Skripsi. Surakarta : Fakultas Geografi UMS

Misqi, M. (2010). Analisis Konstanta Resesi Sungai Bawah Tanah untuk Karakterisasi Pelepasan Komponen Akuifer Karst (Studi Kasus Mataair Beton, Sungai Bawah Tanah Seropan, dan Sungai Bawah Tanah Toto, Kab Gunung Kidul, Propinsi DIY). Skripsi. Yogyakarta : Fakultas Geografi, Universitas Gadjah Mada.

Muliranti, S. dan Pramono Hadi, M. (2013). Kajian Ketersediaan Air Meteorologis Untuk Pemenuhan Kebutuhan Air Domestik di Provinsi Jawa Tengah dan DIY. Diakses tanggal 28 Nopember 2015 dari http://lib.geo.ugm.ac.id/ojs/index.php/jbi/article/do wnload/160/157.

Peraturan Menteri Kesehatan RI Nomor 492/MENKES/PER/IV/2010 tanggal 19 April 2010 tentang Persyaratan Kualitas Air Minum.

Purnama, Setyawan. (2010). Hidrologi Air Tanah. Yogyakarta: Kanisius.
Samodra. (2001). Nilai Strategis Kawasan Karst di Indonesia: Pengelolaan dan Perlindungannya. Bandung : Pusat penelitian dan pengembangan geologi, Badan Penelitian dan Pengembangan Energy Sumberdaya Mineral, Departemen ESDM.

Samodra. (2005). Potensi Sumberdaya Alam Karst Kabupaten Wonogiri Jawa Tengah. Buku Kedua, Bandung : Pusat penelitian dan Pengembangan Geologi, Badan Geologi Departemen ESDM.

Salamat, F. (2005). Evaluasi Potensi Mataair Sebagai Sumber Air Bersih dan Upaya Pelestarian Lingkungan di Pulau Banggai Sulawesi Tengah. Tesis. Yogyakarta : Pascasarjana, UGM.

Sarkol, R. (2010). Kajian Potensi Mataair Sebagai Sumber Air Bersih di Pulau Wamar Kabupaten Kepulauan Aru Provinsi Maluku. Tesis. Yogyakarta : Pascasarjana UGM.

Sejati, Sadewa Purba. (2013). Kajian Potensi Airtanah Di Lereng Selatan Gunungapi Merapi untuk Mencukupi Kebutuhan Air Domestik pada Hunian Sementara. Tesis. Yogyakarta : Pascasarjana UGM.

Setiawan, N. (2007). Penentuan Ukuran Sampel Memakai Rumus Slovin dan Tabel Krecjie-Morgan : Telaah Konsep dan Aplikasinya. Makalah. Bandung : Universitas Padjajaran.

Seyhan, E. (1990). Dasar-Dasar Hidrologi (Terjemahan). Yogyakarta: Gadjah Mada University Press.

Sosrodarsono, S. dan Takeda, K. (1976). Hidrologi untuk Pengairan, (cetakan kesepuluh, 2006). Jakarta : PT. Pradnya Paramita.

Todd, D. K. (1980). Groundwater Hydrology, $2^{\text {nd }}$ Ed. England : John Wiley \& Sons.

Tolman, C. F. (1973). Groundwater. New York: McGraw-Hill Book Company Inc.

Yudistira, A. Dan Adji, T. N. (2012). Kajian Potensi dan Arahan Penggunaan Airtanah untuk Kebutuhan Domestik di Kecamatan Depok Kabupaten Sleman. Diakses tanggal 16 Nopember 2015 dari http://download.portalgaruda.org/article.php?articl $\mathrm{e}=81305 \& \mathrm{val}=4927$.

Youngjun, J, et al. (2008). Impact of Landuse Change on Groundwater Quality in A Typical Karst Watershed of Southwest China, : A Case Study of Xiaojiang Watershed, Yunnan Province. Hydrogeology Journal. 16, 727-735.

Zeffitni. (2012). Agihan Spasial Ekologikal Potensi Airtanah untuk Kebutuhan Domestik di Cekungan Airtanah Palu Provinsi Sulawesi Tengah. Jurnal Manusia dan Lingkungan. 19(2), 105-117. 